to be well attended. Almost every man learns to play some sort of musical instrument. At the time the report was written St. Dunstan's and its annexes contained 578 men, and 434 men had passed through the institution. Of the latter number it is most satisfactory to state that 90 per cent. had been set up in occupations which they had been taught. The greatest attention is paid to the welfare of those trained at St. Dunstan's. For example, they are settled in the industries which they have been taught, and provided with an outfit and with raw material. They are visited regularly and their work supervised, and assistance is given in marketing their goods. The former inmate can earn on the average a fair living wage-many make $£ 2$ or $£ 3$ a week, and quite a number even more than that amount. Well may the report be concluded with W. E. Henley's lines written when stricken with paralysis :

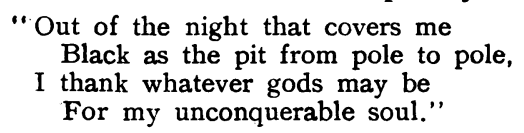

\title{
Ophthalmology in Philadelphia
}

Among other interesting matter, the first number of the American Journal of Ophthalmology, contains a review of the rise and progress of ophthalmology as a speciality in Philadelphia, by Dr. Samuel Risley. The article is of interest on this side of the water where more and more we are becoming acquainted with the excellent work of our colleagues in America. It is not so long ago that the British profession and public looked rather askance at American specialism, but of recent years we have learned to recognize the very excellent work that the American specialist is doing. That scepticism was not confined to those not American is shown by the remark of Risley himself, who says that in the mind of the profession (that is, the American profession) prior to 1870 there existed a deep-seated prejudice against any claim to a special knowledge of the diseases of any organ, and that any such claim relegated the individual to the "unsavoury confines of charlatanism." Risley says: "This hostility to the specialist in medicine was due in large measure to the bizarre, advertisement of the ignorant charlatan; a survival from earlier times of the medical mountebanks whose character and methods had justified the lampoons and caricatures by contemporary poets and novelists in ridicule of the doctor; characterisations which still survived in the memory of the educated portions of the community and rankled in the mind of the doctor of that day, as they do in ours, as an injustice to a learned and philanthropic profession."

Do we not know that a similar, if earlier, internal hostility of the 
profession to the medical or surgical specialist existed in this country? The biographies of British ophthalmologists which have appeared from time to time in THE BRITISH JOURNAL OF OPHTHALMOLOGY show this as regards ophthalmology. We learn a great deal from this article as to the stages in the advancement of knowledge in America, and it is almost certain that if a similar article were written for this country, it would be found that we also had made progress by similar stages from ignorance to what we choose to call knowledge. Yet, what will our successors have to say about it ?

\section{The Halifax Disaster}

In the April number of the American Journal of Ophthalmology a graphic account is given by our colleague, Captain F. Tooke, of Montreal, of his experiences after the recent Halifax disaster. It will well repay perusal. On short notice he left Montreal for Halifax accompanied by a member of the nursing staff of the Royal Victoria Hospital. After a couple of nights spent on the train Halifax was reached. The roof of the railway station had fallen in ; innumerable cars and trucks were wrecked on the sidings, and the travellers were compelled to make their way through a sea of broken glass and over countless obstacles, chiefly wreckage and coffins. The city was wrapped in silence, and the streets were empty. Halifax seemed to be a city of the dead. An area equal to one and a half miles square was laid flat; not a building was left entire, even large trees being shattered. There was not one building in the city without broken glass. Some idea of the force of the explosion may be gathered from the bald statement that the massive anchor of the "Mont Blanc," the ammunition ship laden with petrol and tri-nitro-toluol that exploded after collision with the Belgian relief steamer "Imo," was found three miles from the scene of the disaster. Captain Tooke estimates that 25 per cent. of the casualties were eye cases. The great proportion of these injuries is to be explained by the fact that the glare of the burning petrol on the "Mont Blanc" and the ringing of the fire alarms had drawn many persons to the windows, and when the explosion came later and the glass was blown inward many eyes were damaged. It was a fortunate circumstance, perhaps, that double windows had not been put up for the winter. Captain Tooke gives a list of 48 eye injuries, in many of which operations were necessary. The injuries were from broken glass, and were often associated with incised wounds of the head, face, and neck due to a similar cause, which were almost invariably septic. 1,500 units of antitetanic serum were given, but only on the fifth day after the explosion, since a large enough supply could not be obtained at first. It is satisfactory 